\title{
A GRAMATICALIZAÇÃO DO CONECTOR CONSECUTIVO “CHEGA" NO FALAR FORTALEZENSE
}

\section{THE GRAMMATICALIZATION OF THE CONSECUTIVE CONNECTOR “CHEGA” IN THE SPEECH OF FORTALEZA}

\author{
Júlio César Lima Moreira"
}

Resumo: Expomos no presente trabalho um fenômeno de mudança linguística, observado no falar de Fortaleza. A partir de algumas amostras observadas no falar fortalezense, coletadas pelo autor, e outras do corpus linguístico do NORPOFOR, tomamos por hipótese que, em orações subordinadas, a construção gramatical fonte "que chegou a", encontrada em orações subordinadas consecutivas, sofreu um processo que levou à sua gramaticalização, resultando como produto a forma "chega" invariável e com valor de conector consecutivo. A partir disso, buscamos traçar um provável percurso dessa mudança e desenvolver argumentos que confirmem, plausivelmente, que a forma "chega", no contexto acima descrito, a partir da construção gramatical "que + chegar (flexionado) + a", assumiu outra função, indicar a consequência do fato expresso na oração anterior. Adotamos uma perspectiva teórica plural fundamentada em conceitos da Sociolinguística, da Linguística Centrada no Uso; no modelo teórico da Gramática das Construções e do Funcionalismo Linguístico, de cujo conceito de gramaticalização nos valemos.

Palavras-chave: gramaticalização; conector consecutivo; chega.

ABstract: In the present work, we expose a phenomenon of linguistic change, observed in the speech of Fortaleza. From some data observed in the speech of Fortaleza, collected by the author, and others obtained from the linguistic corpus of the NORPOFOR, we assume that, in subordinate clauses, the sequence "que + chegar (inflected) + $a$ " (literally, "that comes to"), suffered a process that led to its grammaticalization, resulting in "chega" (literally, "it comes"), invariable and with the value of a consecutive connector. From this, we seek to trace a probable path of this change and develop arguments that plausibly confirm that the form "chega", in the context described above, from the grammatical construction "que + chegar (inflected) $+a$ " assumed another function, to

\footnotetext{
"Mestre em Linguística no Programa de Pós-Graduação em Linguística da Universidade Federal do Ceará (PPGL-UFC). Professor da graduação no Curso Licenciatura em Letras Português-Inglês do Instituto Federal do Ceará (IFCE) no campus Tabuleiro do Norte. E-mail: julio.moreira@ifce.edu.br.
} 
indicate the consequence of the fact expressed in the previous clause. We adopted a plural theoretical perspective based on concepts of Sociolinguistics, of the UsageCentric Linguistics, in the theoretical model of the Grammar of Constructions, and of the Linguistic Functionalism, whose concept of grammaticalization we used.

KEYwoRDs: grammaticalization; consecutive connector; arrive.

\section{INTRODUÇÃo}

A relação existente entre língua, sociedade e cultura é inquestionável e considerada uma premissa nos estudos linguísticos da corrente funcionalista. Nesse sentido, a língua é considerada, portanto, um produto histórico e cultural de um determinado povo ou comunidade linguística. A partir de uma perspectiva pancrônica, ao passo que a língua é produto, também o é processo, pois é na fala onde aquela se "concretiza" e se atualiza continuamente, sofrendo intervenções daqueles que a usam. No entanto, essas intervenções nem sempre vingam e são incorporadas ao sistema linguístico da comunidade, seja um elemento lexical ou funcional (gramatical). Essa variação, concebida na perspectiva funcionalista da linguagem como inerente ao sistema linguístico, acarreta mudança linguística caso seja incorporada e difundida pelos membros da comunidade de fala que a usam.

Um desses exemplos de mudança linguística que ora trazemos é observável na comunidade de fala de Fortaleza. Trata-se da ocorrência de um fenômeno observado em orações subordinadas com verbo da principal no pretérito, que consiste no uso da forma chega, que, após sofrer gramaticalização a partir da construção original que chegou $a$, passa a cumprir sozinha a função de conjunção consecutiva e não mais apresentar características morfossintáticas da categoria verbo a que pertencia originalmente. Fazemos esse recorte considerando que, para outras cláusulas subordinadas cujos verbos na principal não estejam no pretérito, possa haver outras hipóteses concorrentes que expliquem a gramaticalização do chega, não sendo o objetivo do presente trabalho explorar outros contextos de gramaticalização desse item gramatical.

Embora seja observável este fenômeno como recorrente em outras regiões do estado do Ceará e em outras unidades federativas do nordeste brasileiro, nosso escopo é analisá-lo na comunidade de fala de Fortaleza, delimitando-o; assim, conseguimos viabilizar a exposição da hipótese.

Ademais, foge ao escopo do presente trabalho fazer um estudo de caráter mais aprofundado, com exaustiva massa de dados e com apresentação de resultados quantitativos da descrição e análise do fenômeno. Mas, sim, pretendemos, de forma mais qualitativa e preocupados em analisar o vernáculo, baseado em ocorrências presentes de uma pequena amostra do corpus instituído pelo NORPOFOR, e com exemplos de nossa própria observação, apontar que essas ocorrências (forma chega com valor de conector oracional) surgem com frequência 
na fala dos indivíduos, demonstrando a forma chega, conector consecutivo, como já integrante do sistema linguístico da comunidade de fala em foco. Desse modo, responderemos a seguir alguns questionamentos que julgamos pertinentes para a melhor compreensão da presente exposição, a saber: I - Podemos considerar a forma chega como efetivamente gramaticalizada no repertório dos falantes de Fortaleza, ou seja, a ascensão da forma chega ao atingir um uso mais gramatical (verbo > conjunção) caracterizaria um processo de gramaticalização já consolidado? II - A forma-fonte que lhe deu origem é a construção que chegou a? III - Qual a trajetória de percurso, i. e., quais as etapas do processo e quais mecanismos explicariam essa gramaticalização? E por fim: IV - como essa gramaticalização se acomodou no contexto sintagmático em que se enquadra?

Buscando responder os questionamentos, tomamos como hipótese básica que essa referida forma linguística haja passado por um processo de gramaticalização e já esteja incorporada ao repertório dos falantes fortalezenses, dada a frequência de ocorrência observada no vernáculo e aqui trazidos como exemplos dessa observação direta, além da amostra do corpus citado. Quanto ao segundo e terceiro questionamentos, tomamos como pressuposto que a construção que chegou a deu origem à forma chega atuando como conjunção consecutiva por funcionar como um bloco (concebida como uma unidade linguística) e passar a atuar como um lexema gramatical e, com isso, o processo de mudança consolida-se por etapas, incluindo as de univerbação, erosão fonética e de implicatura ${ }^{1}$ e segue até culminar na forma chega inserida no paradigma dos conectivos consecutivos. E, por fim, respondendo à última problematização, acreditamos que a gramaticalização de chega foi a ignição para reanálises no sistema para acomodar a nova forma, a qual passaria a ocorrer e passou a exigir a mudança do verbo na oração encaixada, cuja ocorrência antes da gramaticalização se dava com o verbo no infinitivo, como em: Ela comeu tanto que chegou a passar mal. E, com a mudança trazida pela gramaticalização do chega conjunção, temos: Ela comeu tanto chega passou mal, sofrendo mudança na forma verbal do verbo chegar (chegou > chega), supressão da preposição (chegou a > chega) e alteração na flexão do verbo na oração subordinada (passar mal > passou mal).

Nas seções seguintes, fazemos uma breve exposição do nosso referencial teórico, passamos pela Sociolinguística Variacionista e sua interface com o Funcionalismo Linguístico no estudo sobre a mudança linguística. Outrossim, consideramos o conceito teórico de gramática das construções, o qual justifica a nossa segunda hipótese. Ademais, exploramos conceitos da Linguística Centrada no Uso, que complementam a presente análise com vistas a explicar as etapas do processo de mudança em foco.

\footnotetext{
${ }^{1}$ A esse respeito, Martelotta (2011, p. 66) diz que a implicatura conversacional se trata de um tipo de inferência segundo a qual o significado de uma frase não corresponde ao sentido literal, sendo deduzido do contexto. Nesse caso, consideramos que chega passou por implicatura conversacional como um estágio inicial e, posteriormente, dada implicatura conversacional com a frequência de uso e a extensão para outros ambientes de uso passou à etapa de consolidação e inserção no paradigma dos conectores consecutivos no falar fortalezense.
} 
Em seguida, expomos a classificação dada ao vocábulo chega por alguns dicionários. Na sequência, mostramos e analisamos o fenômeno ora observado no vernáculo de Fortaleza, a partir de casos em que a forma de terceira pessoa do singular do presente do indicativo do verbo chegar assume a função de conjunção consecutiva em orações subordinadas sem prejuízo para o sentido esperado da oração. Oportunamente, traçamos um percurso da mudança, uma projeção das etapas até a efetiva gramaticalização que aqui defendemos como efetivada e culminamos com a conclusão com a apreciação do presente trabalho e sua contribuição para os estudos sobre gramaticalização do verbo chegar.

\section{O CARÁTER DINÂMICO DA LÍNGUA - FENÔMENOS DE VARIAÇÃO E DE MUDANÇA LINGUÍSTICA}

Partindo de uma perspectiva funcionalista da linguagem, a língua está constante e ininterruptamente submetida à instabilidade no seu sistema. A língua é dinâmica e heterogênea e se atualiza na fala, que é, nessa relação, simultaneamente processo e produto. Nesse sentido, a variação e mudança linguísticas são inerentes a qualquer língua natural. Convém destacar, valendo-nos de um pressuposto da Sociolinguística Variacionista, que nem toda variação implica mudança, mas que toda mudança provém de variação. O nosso objeto de estudo, por hipótese, em seu percurso, teria passado por um processo de variação que culminou em mudança consolidada no sistema, a qual, na perspectiva do Funcionalismo, ocorreu por gramaticalização.

A nosso ver, e conforme o concebem os sociolinguistas, baseados no princípio do uniformitarismo proposto pelos neogramáticos, há padrões de regularidade na mudança linguística. A partir desse princípio e considerando por analogia outros fenômenos de gramaticalização que mostram um padrão de mudança que segue o cline: verbo > conjunção, ${ }^{2}$ buscaremos traçar um percurso de mudança da gramaticalização de chega no falar fortalezense.

Para tratarmos do fenômeno ora em foco, consideramos o conceito de comunidade de fala proposto por Guy (2001). Para o autor, uma comunidade de fala define-se como um grupo de falantes que compartilham características linguísticas que distinguem seu grupo de outros e partilham normas e atitudes em relação ao uso da língua e que interagem mais entre si do que com outros grupos. A partir desse conceito, delimitamos nosso estudo à comunidade de fala de Fortaleza.

Outrossim, é oportuno conhecer a classificação já consolidada dos tipos de mudança linguística

- Mudança semântica: mudança de um significado a outro ou ampliação/redução de traços que compõem um significado.

\footnotetext{
${ }^{2}$ Coerente com a proposta de ordenação de categorias cognitivas de Heine (1991), cuja orientação é unidirecional e vai do mais concreto ao mais abstrato. $\mathrm{O}$ verbo representa processos, ações e é mais concreto do que as conjunções.
} 
- Mudança categorial: mudança de uma categoria menos gramatical a outra mais gramatical (de verbo pleno a conjunção, por exemplo).

- Mudança substitutiva: troca de uma forma por outra na codificação de uma função (considerando o paradigma pronominal dos pronomes pessoais na função de sujeito e tomando como foco a comunidade de falantes de São Paulo em sua expressão falada na sincronia atual, observa-se claramente que o pronome você ou sua forma concorrente cê praticamente já substituíram o tu na representação da $2^{a}$ pessoa do discurso. Isso representaria um exemplo de mudança substitutiva que implica um estágio de coocorrência).

Tradicionalmente, dois ramos da Linguística contemplam o caráter dinâmico e emergente da língua e se debruçam sobre fenômenos de mudança linguística: a Sociolinguistica Variacionista, que se ocuparia mais particularmente da mudança substitutiva e o Funcionalismo Linguístico (através do conceito de gramaticalização), que se ocuparia da mudança categorial. Nosso fenômeno, a partir da perspectiva adotada, se enquadraria nesse segundo grupo abrangido pela gramaticalização. E, assim, sofreria mudança categorial, por passar da categoria verbo à de conector oracional (conjunção). Podemos ilustrar a mudança substitutiva através do esquema 1 e a mudança categorial através do esquema 2:

\section{Esquema 1}

$$
\mathrm{A}-\mathrm{X}>\mathrm{A} / \mathrm{B}-\mathrm{X}>\mathrm{B}-\mathrm{X}
$$

\section{Esquema 2}

$\mathrm{A}-\mathrm{X}>\mathrm{A}-\mathrm{X} / \mathrm{Y}>\mathrm{A}-\mathrm{Y}$

No esquema 1 acima, A e B seriam as variantes que formam uma variável dependente que concorrem na expressão de um significado com mesmo valor de verdade (representado por X). Quando se concretiza a mudança, a variante conservadora, no caso A, é substituída pela variante inovadora, B. Já no esquema 2, a mesma forma ou construção linguística passa a representar mais de uma função ou significado ( $\mathrm{X}$ e $\mathrm{Y}$ ) em contextos concorrentes, em nosso caso a forma chega com valor de verbo e de conector. Há o momento de transição, e quando se perpetua a mudança, passa a atuar como elemento de outra categoria, com outra função ou significados diferentes. Essa mudança categorial, em que ocorre inerentemente um estágio de transição, ${ }^{3}$ é o que buscamos representar no presente estudo, por observarmos a forma verbal flexionada chega atuando com função diferente da original, a de outra categoria mais

\footnotetext{
${ }^{3} \mathrm{~A}$ esse respeito, vale destacar que a mudança, assim como se dá na perspectiva do Funcionalismo Linguístico em cuja gramaticalização há um estágio de transição, na perspectiva da Sociolinguística igualmente se dá inicialmente um processo de variação antes de uma mudança consolidar-se. Para a Sociolinguística, que se volta aos fenômenos de variação e mudança, cabe a expressão: toda mudança implica um período anterior de variação, mas nem toda variação implica mudança. Conferir Weinreich, Labov e Herzog (2009 [1968], p. 108) sobre o problema da transição.
} 
gramatical, a de conjunção, tornando-se, assim, invariável. Se considerado o esquema 2 , um item representa dois significados ou funções gramaticais diferentes.

Ainda fazendo alusão à Sociolinguística Variacionista e dada sua relevância para fundamentar nossa hipótese, faz-se oportuno mencionar o princípio do uniformitarismo, segundo o qual as leis que regem as mudanças hoje atuaram igualmente no passado. Para Paiva e Duarte (2003), esse princípio implica que

as forças que impulsionam as mudanças linguísticas em germe no presente são as mesmas que impulsionaram mudanças operadas no passado. O que, em outros termos, equivale a dizer que a língua de ontem não era, em sua essência, diferente da língua de hoje. Assim, se é verdade que a compreensão dos fatos passados auxilia na compreensão dos fatos do presente, o inverso também é verdadeiro: o presente pode elucidar processos de mudança já concluídos. (PAIVA; DUARTE, 2003, p. 183, grifos nossos).

Nesse sentido, de forma dedutiva, tomando exemplos de construções gramaticais que sofreram gramaticalização originando elementos ainda mais gramaticais, seguindo o cline de mudança (HEINE, 1991), acreditamos que o mesmo tenha ocorrido com o chega. As mesmas pressões relativas à frequência de uso, os processos de univerbação e de erosão fonética atuantes hoje do mesmo modo atuaram no passado. A partir da observação da forma chega no plano sincrônico atual no vernáculo fortalezense, originada do verbo chegar, deduzimos que, por analogia a outros fenômenos cujas construções resultaram em conjunções como: em boa hora > embora, a construção que chegou a seria a forma-fonte e a partir de então deduzimos seu percurso de mudança.

Embora se exija uma maior exposição para conhecer os pressupostos teórico-metodológicos da Sociolinguistica Variacionista para o nosso propósito, o exposto nos dá um panorama e o subsídio necessário para a apresentação do fenômeno estudado.

\section{Linguística Centrada no Uso}

Oportunamente, também nos baseamos nos pressupostos da Linguística Centrada no Uso. Alguns autores, como Tomasello (2003), também utilizam o termo Linguística Cognitivo-Funcional. A Linguística Centrada no Uso (doravante LCU), segundo Martelotta (2011, p. 56), seria

um tipo de abordagem que considera haver uma relação estreita entre a estrutura das línguas e o uso que os falantes fazem delas nos contextos reais de comunicação. Um tipo de abordagem que não se limita à observação de aspectos formais, ou da difusão das formas pela estrutura 
social, incorporando em suas análises, dados semânticos, pragmáticos e discursivos.

A língua é vista como dinâmica e emergente, fruto da criatividade humana e da ritualização dos eventos de uso. Nasce da adaptação das habilidades cognitivas humanas a eventos de comunicação específicos e se desenvolve a partir da repetição e ritualização desses eventos (MARTELOTTA, 2011, p. 57). Segundo esse modelo, a gramática de uma língua constitui um conjunto de princípios dinâmicos que se associam a rotinas cognitivas que são moldadas, mantidas e modificadas pelo uso (MARTELOTTA, 2011, p. 58). Dito de outro modo, a LCU concebe o sistema como sendo adaptativo-funcional, onde a gramática seria emergente, refletindo a criatividade humana para encontrar a forma ótima e expressiva de comunicação em diferentes contextos (MARTELOTTA, 2011, p. 72). Criatividade aqui entendida como capacidade cognitiva que capacita o indivíduo em tempo real na situação comunicativa a modificar, adaptar o sistema linguístico que tem à disposição, lançando mão de mecanismos como a metonímia e metáfora de acordo com os propósitos comunicativos específicos, e de acordo com o interlocutor, dando pistas contextuais que sejam apreensíveis por esse interlocutor, valendo-se de diferentes mecanismos de inferência.

Podemos inferir, então, a partir da definição do autor, que a Linguística Centrada no Uso (LCU) abrangeria também como escopo o estudo da variação e mudança linguística, no entanto, difere da proposta da Sociolinguística Variacionista, que é essencialmente quantitativa com um aparato metodológico bem objetivo e se atém a um mapeamento de um determinado fenômeno de mudança e a influência de variáveis linguísticas e sociais nesse processo. Apesar da LCU considerar a influência do uso que os indivíduos fazem incidir sobre o sistema linguístico e como consequência possível incidir em mudança linguística, não se estabelece aqui uma variável dependente sobre a qual grupos de fatores interfeririam. Em nosso caso específico, não hipotetizamos sobre qual ou quais variáveis explicariam o processo de mudança da forma chega. Partimos aqui do pressuposto da mudança consolidada na comunidade de fala em foco via processo de gramaticalização fazendo uma análise qualitativa sem o objetivo de representar a distribuição na estrutura social a ocorrência do fenômeno e quais contextos linguísticos interferem nesse uso como se dá na perspectiva da Sociolinguística Variacionista.

Contemplando aspectos semânticos, pragmáticos e discursivos, a abordagem da LCU volta-se ao indivíduo e contempla os processos cognitivos on-line inerentes ao processamento da mensagem e recepção da mensagem e o fruto dessa interação moldado pelo uso.

Portanto, buscou-se enfatizar que a gramaticalização ocorrida da forma chega é explicável com base em processos cognitivos, em especial, as implicaturas conversacionais, com coordenadas metonímicas e inferenciais, obedecendo aos princípios da informatividade e da economia, permitindo ao ouvinte extrair os significados necessários à compreensão da 
asserção (GONÇALVES et al., 2007, p. 33). E sendo, por fim, ratificadas pela frequência do uso, adquiridas e convencionadas entre os falantes da comunidade linguística em foco.

E difere do Funcionalismo, ampliando o escopo da gramaticalização no tratamento da mudança, pois, além de considerar o contexto pragmático, ou seja, as pressões do uso na situação comunicativa, recorre a fatores cognitivos para explicar o processamento das sentenças e um consequente fenômeno de mudança.

Em suma, é possível observarmos o fenômeno através do prisma da gramaticalização, apontando as etapas da mudança aliados aos pressupostos da LCU para projetarmos as motivações da mudança em foco, de modo a contemplar a ação dos processos cognitivos como fator contribuinte nesse processo.

\section{Gramática das Construções}

Ao mencionarmos, na seção anterior, a vertente da Linguística Cognitiva, consideramos, outrossim, ser relevante mencionar um modelo teórico dessa vertente linguística denominado gramática das construções, o qual propõe que "as expressões linguísticas desde as mais simples até as mais complexas constituem unidades simbólicas baseadas em correspondências entre forma e significado" (FERRARI, 2011, p. 129).

Sousa (2010) afirma que dois princípios fundamentais caracterizam as gramáticas de construções: (1) a ideia de que a unidade básica de operação sintática é a "construção", definida como a unidade linguística formada por uma estrutura complexa e seu significado (CROFT, 2001; GOLDBERG, 1995, 2006); e (2) a ideia de que essas construções estão organizadas em uma rede conceptual na mente do falante, formando um repertório. Cada construção gramatical seria entendida como uma unidade linguística. Um exemplo prototípico de construções gramaticais complexas são as expressões idiomáticas cujo valor/significado não é apreensível a partir dos significados dos itens que as compõem tomados isoladamente, mas sim como um todo.

Para Martelotta (2011), uma construção gramatical é entendida como uma ou a combinação de unidades formais fixas padronizadas e portadoras de significado, incluindo aí características pragmático-discursivas. E que o significado dessas combinações de unidades formais ou construções não é o resultado da soma dos sentidos dos elementos que as compõem (MARTELOTTA, 2011, p. 59).

As construções gramaticais podem ser simples, formadas de uma só palavra, ou complexas, por mais de uma, que, juntas, formariam um bloco de palavras com um só significado e esse significado não seria a soma do valor literal que possui cada item, ou seja, não composicional. Podemos citar como um exemplo mais ilustrativo as expressões idiomáticas, tais como "pisar na bola”. João pisou na bola mais uma vez. A construção "pisar na bola" já está convencionada e enraizada no português com o sentido diferente do que a junção dos significados dos itens 
que a compõem, indicando o cometimento de uma falha, um erro e não o ato de pisar com o pé um objeto esférico (uma bola). Teríamos no esquema 3, a seguir, uma ilustração dessa relação forma/significado

\section{Esquema 3}

\section{Pisar na bola / COMETER UMA GAFE, UM ERRO}

Para Croft e Cruse (2004 apud SOUSA, 2010), uma construção consiste em um par forma/significado, como o exposto no esquema 3 , de alguma maneira convencionalizado para uma determinada comunidade linguística. O termo "significado" diz respeito a todos os aspectos funcionais e conceptuais da construção linguística, desde os situacionais até os discursivos e pragmáticos.

Sobre a relação forma/significado e os elementos que compõem dada construção, Fried e Östman, (2004 apud SOUSA, 2010, p. 3) afirmam que:

as gramáticas de construções concebem o par forma/função (ou forma/ significado) como uma unidade indivisível, ele não pode, consequentemente, ser representado em termos de componentes distintos, assim como geralmente é feito em modelos composicionais.

Nesse sentido, no modelo das gramáticas de construções, o significado de uma dada construção não é dado pela soma e da ligação dos significados individuais dos termos que compõem dada construção.

Justifica-se aqui a consideração desse modelo teórico por concebermos "que chegou a" uma construção gramatical na perspectiva apontada e que esta passou por processo de gramaticalização, resultando na conjunção consecutiva "chega" a partir de processos de reanálise e de implicaturas causados pelos contextos de uso e ratificados pela frequência.

Portanto, através desses pressupostos, buscaremos demonstrar a gramaticalização da forma "chega" projetando um percurso hipotético de mudança no passado e o que poderia plausivelmente explicá-lo. Falamos sobre gramaticalização até então. Mas o que seria gramaticalização? Exporemos esse conceito a seguir visando a deixar clara a perspectiva adotada neste estudo.

\section{GRAMATICALIZAÇÃo: UM PROCESSO UNIVERSAL E REGULAR DA MUDANÇA LINGUíSTICA}

Após a exposição nas seções anteriores sobre os tipos de mudança, por ora convém destacar que há dois modos pelos quais formas gramaticais novas emergem: a) inovação analógica - novos paradigmas vêm à tona através de semelhanças formais com paradigmas já existentes; b) gramaticalização - do ponto de vista diacrônico, é um processo que transforma lexemas em formativos gramaticais e torna-os, por sua vez, mais gramaticais ainda (LEHMAN, 1982). 
A língua é um fenômeno que se constitui historicamente. Nesse sentido, a gramática de uma língua é um fenômeno histórico por extensão, fruto de desenvolvimentos históricos, que denotam variação e mudança linguística. Lichtenberk (1991, p. 38) concebe a gramaticalização como um processo que conduz a certas mudanças na gramática da língua. Para o autor, as consequências do processo de gramaticalização, portanto, a mudança efetivada, refletem esse caráter mutante das gramáticas das línguas naturais, por extensão, o caráter de mutabilidade do próprio sistema linguístico. Para Lichtenberk, a gramaticalização, essencialmente apreensível no plano diacrônico, é um tipo de mudança que implica alterações para as categorias morfossintáticas da língua e, por conseguinte, para a gramática. Essas consequências para o autor são: i) emergência de uma nova categoria gramatical; ii) perda de uma categoria gramatical existente; e iii) mudança em um membro da categoria gramatical (LICHTENBERK, 1991, p. 38). Por sua vez, Lehmann considera outras três consequências da gramaticalização: i) passagem de um elemento menos gramatical para um elemento mais gramatical; ii) perda de característica fonológica e semântica; iii) Diminuição de liberdade da manipulação do elemento. O elemento em processo de gramaticalização passa a fazer parte de um paradigma, tornando-se cada vez mais obrigatório em certas construções e ocupando uma posição mais fixa (LEHMANN, 1991, p. 493).

A nosso ver, o conceito de gramaticalização do Funcionalismo Linguístico aliado a pressupostos da Linguística Centrada no Uso (LCU) dão conta de explicar a hipótese ora sustentada, a de que a forma "chega" com valor de conector consecutivo, em orações subordinadas cuja oração principal se refere ao passado, é uma forma gramaticalizada derivada da construção "que chegou a" já consolidada no falar fortalezense. Consideramos, neste estudo, a gramaticalização como um processo que implica mudança dentro do sistema, visando ao seu equilíbrio, de modo a suprir formas para as funções não satisfeitas dentro de si em determinado estágio no plano diacrônico ou como resultado da criatividade humana em busca de incutir maior expressividade ou ampliar a diversidade em determinado paradigma (entenda-se aqui categoria/função gramatical). Isso nos remete ao entendimento de Heine et al. sobre gramaticalização. Para ele, o processo de gramaticalização ocorre devido às necessidades de comunicação não satisfeitas pelas formas existentes no sistema linguístico e à existência de conteúdos cognitivos para os quais não existem designações linguísticas adequadas (HEINE et al, 1991, p. 19-30).

Para Heine e Reh (1984, p. 15), “a gramaticalização é um processo em que unidades linguísticas perdem em complexidade semântica, significação pragmática, liberdade sintática e substância fonética, respectivamente". Consideramos a definição de Heine e Reh adequada ao nosso propósito, pois permite considerar unidades linguísticas como construções gramaticais simples ou complexas. Desse modo, construções complexas sofreriam gramaticalização e estamos tomando como hipótese a gramaticalização da construção complexa "que chegou a” observável em (1) comutável por “chega”, como está em (1a). 
(1) Macho, na hora o pivete correu tão depressa que chegou a escapar da polícia (exemplo do próprio autor). ${ }^{4}$

(1a) Macho, na hora o pivete correu tão depressa chega escapou da polícia (exemplo do próprio autor). ${ }^{5}$

Destacamos que o processo de gramaticalização é normalmente caracterizado como unidirecional, no sentido de que elementos representacionais (léxico) se tornam gramaticais, ou menos gramaticais se tornam mais gramaticais, e não o contrário. Esse é um dos pontos mais debatidos sobre o processo de gramaticalização (MARTELOTTA, 2011, p. 106). Para Hopper e Traugott (1993, p. 95), "existe uma relação entre dois estágios A e B, tal que A ocorre antes de B, mas não o inverso. Isso é o que se entende por unidirecionalidade". Sobre a unidirecionalidade, Gonçalves et al. (2007, p. 37) afirmam que, sendo o princípio uma lei geral, determinante na constituição e identificação de um fenômeno, parece que ao fenômeno de gramaticalização só pode ser atribuído um único e fundamental princípio, o da unidirecionalidade.

Hopper e Traugott (1993) esboçaram um esquema para representar esse "cline de gramaticalidade":

\section{Esquema 4}

palavra lexical $\rightarrow$ palavra gramatical $\rightarrow$ clítico $\rightarrow$ afixo flexional

Nesse sentido, a gramaticalização sempre se origina de um item lexical para um gramatical ou de um menos gramatical para um mais gramatical, ou seja, do mais concreto para o mais abstrato.

Sendo a gramaticalização um processo, isso implica que há etapas, melhor dizendo, estágios, e o conjunto desses estágios se denomina normalmente cline. No percurso da forma linguística de [- gramatical] para [+ gramatical] ou de lexical para gramatical, há um estágio de transição, pois a mudança é gradativa. Para Lehmann (1982), esses estágios seriam:

\section{Esquema 5}

Sintetização > morfologização > desmorfologização.

Consideramos em nossa hipótese que a forma "chega" já se encontra no estágio final de gramaticalização, no qual o item chegou da construção "que chegou a” perde a desinência

\footnotetext{
${ }^{4}$ Entenda-se exemplo do próprio autor, os exemplos observados ou pronunciados por mim no dia-a-dia de forma espontânea em diversos ambientes na cidade de Fortaleza.

${ }^{5}$ Observa-se que, no exemplo (1a), houve necessariamente uma mudança no contexto linguístico, o verbo da oração encaixada obrigatoriamente vem conjugado e não no infinitivo como em (1). Isso seria uma reanálise linguística feita para o encaixe da mudança, a qual trataremos mais adiante.
} 
número-pessoal (desmorfologização) ${ }^{6}$ e força uma reanálise sintagmática para ajustar-se a essa mudança. Como ilustrado nos exemplos (1) e (1a).

Mas o que motiva a gramaticalização? Para Martelotta (2011, p. 109-112), seriam as seguintes forças motivadoras da gramaticalização: a) necessidade de expressar domínios abstratos da cognição em termos de domínios concretos; b) negociação do sentido por falante e ouvinte no ato da comunicação; c) tendência dos ouvintes para selecionar estruturas ótimas; d) tendência dos falantes para usar expressões novas e extravagantes; e) iconicidade, marcação e frequência.

Para nós, aplicam-se ao fenômeno estudado em especial as motivações a), c) e d). Em a), a expressão de uma relação de consequência valor mais abstrato do que o valor de movimento espacial originalmente representado pela forma do verbo chegar. Em c), a forma "chega" como conector consecutivo é materialmente mais otimizada do que a forma "que chegou a". Em d), por ser uma forma nova com mais valor expressivo e destacar-se das demais formas do paradigma conectores consecutivos disponíveis in absentia, e por não pertencer ao quadro da variedade padrão da língua portuguesa, caracteriza-se então como uma forma extravagante, inovadora e, assim, afirmando-se uma motivação a mais para seu uso.

Passamos aos parâmetros da gramaticalização para exemplificar a adequação do fenômeno estudado ao processo de gramaticalização. Há diferentes classificações. Segundo Heine e Kuteva (2007, apud MARTELOTTA, 2011, p. 107) quatro parâmetros caracterizam o processo de gramaticalização. Resumindo-os, seriam os seguintes:

Extensão: As construções ou itens linguísticos passariam a estender seu uso em novos contextos e gradualmente passariam a veicular novos significados. Segue o princípio da exploração de velhos meios para novas funções, de Werner e Kaplan (1963). Em nosso caso, teríamos o verbo chegar passando a atuar como uma forma expletiva ou de realce junto à conjunção que na expressão da consecução, dado o estatuto semântico do verbo chegar indicar culminância de ato ou processo que prescinde um deslocamento espacial/temporal. Seria um reforço da conjunção que, como observamos no exemplo (2a):

(2) Ela 'tava tão cansada que ficou até de noite dormindo (exemplo do próprio autor).

(2a) Ela 'tava tão cansada que chegou a ficar até de noite dormindo (exemplo do próprio autor).

Em (2a), o acréscimo do verbo junto à conjunção enfatiza o processo focado no agente, mas não muda o sentido da proposição.

(2b) Ela 'tava tão cansada chega ficou até de noite dormindo (exemplo do próprio autor).

${ }^{6}$ Vide Gonçalves et al. (2007, p. 31). 
No exemplo (2b), observa-se a presença do chega em plena substituição da locução conjuntiva consecutiva e com o mesmo valor do que em (2). Em (2a), o chegou concorda com o sujeito da principal e denota ainda foco no agente "Ela" da oração principal e oculto na subordinada. Já em (2b), além de ser mais fixo e menos gramatical, por exemplo, já não concorda com o sujeito Ela. Em (2b), temos mais claro um valor de apreciação por parte do enunciador, como se fosse um modalizador, em que o chega parece ser uma apreciação valorativa do enunciador para enfatizar a consequência contida na oração encaixada.

Dessemantização: Os elementos em processo de gramaticalização perdem gradualmente valor representacional da forma-fonte e passam a assumir novo sentido a partir de seu uso em outro contexto. Em (2b), não se observa o significado normalmente atribuído ao verbo chegar, cujo valor seria o de culminância de uma ação ou processo de deslocamento espacial por parte de um agente ou objeto. Em (2b), o chega é um conector oracional que correlaciona a oração principal com a encaixada, atribuindo-lhe a ideia de consequência e denota um certo valor apreciativo do enunciador sobre a oração encaixada.

Decategorização: De acordo com esse parâmetro, o item perde propriedades originais da classe morfossintática da forma-fonte e passa a assumir novas características morfossintáticas ou discursivas. Como vimos em (2b), o uso da forma chega passa a se estender na comunidade de fala em questão com um novo uso e nova função gramatical, atribuindo-lhe a inserção em novo grupo paradigmático, o das conjunções, tornando-se mais fixo e sem a flexão inerente dos verbos do qual se originou com a reanálise do sintagma em que se encaixa como conector consecutivo antes preenchido pela forma-fonte "que chegou a".

Erosão fonética: Caracteriza-se pela perda de substância fonética e tende à fusão e condensação. Por exemplo, a construção "que chegou a" reduzir-se a "chega". Com a frequência de uso e a ritualização da construção, pressupomos o percurso nas seguintes etapas.

(i) Inicialmente, a erosão fonética nos eventos de uso observáveis na fala se deu entre que chegou a > que chego'a > que chega: (com o a prolongado).

(ii) Em um segundo momento, há ocorrência de que chega, que pouco a pouco passou-se a observar também com a presença somente do chega. Seria um momento de transição à consolidação da nova forma.

(iii) Em um estágio final, tem-se a ratificação do chega como sendo considerado um elemento do paradigma conector consecutivo no vernáculo fortalezense.

Acrescentamos, baseados em Martelotta (2011, p. 21), que, após o processo de erosão fonética, o fenômeno ora estudado passa pelo mecanismo de univerbação, que ocorre no nível morfossintático e se dá a partir do processo de aglutinação, em que a expressão "que chegou a" torna-se uma palavra única. Esse fenômeno assemelha-se ao sofrido na gramaticalização do "embora" a partir da construção "em boa hora".?

${ }^{7}$ Sobre esse assunto, veja a análise do percurso da mudança que Martelotta (2011, p. 21-25) expõe. 
Vimos com brevidade algumas considerações sobre o processo de gramaticalização, definição, parâmetros, motivações, dada a limitação de espaço e objetivo deste texto. ${ }^{8}$ Mais adiante trataremos mais sobre o fenômeno da gramaticalização. Passamos a seguir ao tratamento dado pelos dicionários sobre o vocábulo chega.

\section{VALOR DE DICIONÁRIO DO VOCÁBULO CHEGA}

Expomos a seguir a definição que alguns dicionários trazem da forma chega. Como observaremos nos excertos, nenhum deles considera o chega como conector consecutivo, nem como um regionalismo peculiar do falar nordestino, em especial do fortalezense.

(A) (derivação regressiva de chegar) substantivo feminino

1. [Informal] Repreensão, censura, descompostura.

2. Combate de bois (ex.: assistimos a uma chega de bois barrosões; o campo de chegas é vedado).

3. [Antigo] Citação para juízo.

4. interjeição. Expressão usada para mandar parar uma ação ou para fazer calar. = BASTA

(PRIBERAM, 2013)

(B) (ê). [Dev. de chegar]

S. m. ef.

1.Fam. V. repreensão (1). [No Brasil é, em geral, do gên. masc.]

Prep.

2.Bras. Pop. Até, mesmo.

3. Interj. Não mais; basta:

(HOLANDA, 1999)

(C) che.ga

$\boldsymbol{s f}$ (der regressiva de chegar) 1 fam Censura, crítica, reprimenda. 2 Dir ant Intimação judicial por causa de dívidas. interj Basta! Até dizer chega: que se fez até ao fim.

(MICHAELIS, 2009)

Constata-se, a partir dos três dicionários listados, que a forma chega não é considerada, nem mesmo reconhecida como um regionalismo que atuaria como conjunção consecutiva por nenhum dos dicionários acima, além de outros não mencionados, diferentemente do que se observa no falar fortalezense, em outras regiões no Ceará e em outras cidades do nordeste

\footnotetext{
${ }^{8}$ Para uma compreensão mais detalhada do fenômeno de gramaticalização, sugerimos a leitura esclarecedora do livro Introdução à Gramaticalização (GONÇALVES et al., 2007).
} 
brasileiro. Destaca-se a ausência de um trabalho descritivo mais fiel e detalhado sobre o fenômeno ora em foco em outras variedades do português brasileiro.

\section{A gramaticalização do CHEGa NO FalaR FORTALEZENSE}

Baseamos nossa análise a partir de exemplos colhidos da observação direta do falar fortalezense de maneira assistemática em situações diferentes, incluindo amostras de conversas em ambientes diferentes, uma música popular de um grupo do gênero "arrochadeira", reflexo da fala popular, e assim, registrados pelo autor. Também obtivemos uma pequena amostra de três entrevistas do corpus do projeto Norma Oral do Português Popular de Fortaleza (NORPOFOR) ${ }^{9}$ (ARAÚJO, 2011). O referido projeto, desenvolvido nos moldes teórico-metodológicos da Sociolinguística Variacionista, que visa ao registro autêntico da língua falada e com o intuito de subsidiar a descrição e a análise de fenômenos variáveis no português falado de Fortaleza-CE, contemplando os diferentes níveis da estrutura linguística desde o léxico a aspectos morfossintáticos. Esse projeto objetiva também compreender como os mecanismos linguísticos e extralinguísticos contribuem para os fenômenos da variação e mudança em progresso. O corpus é composto de 197 informantes estratificados por sexo, idade, escolaridade e tipo de registro. Não houve ainda a publicação do referido corpus. A referência disponibilizada sobre o NORPOFOR é relativa ao trabalho da autora, descrevendo a metodologia de composição do corpus.

Tivemos acesso a apenas três entrevistas. Nesses inquéritos, encontramos 15 ocorrências da forma chega, mas sendo 12 delas descartadas, pois teriam o valor original da forma flexionada na terceira pessoa do presente do indicativo. Destaco que não apareceram dentro da construção "que chegou a". As demais três ocorrências estariam funcionando como conjunção consecutiva, confirmando nossa hipótese da incidência dessa forma como conjunção consecutiva. Se partíssemos da perspectiva da Sociolinguística Variacionista, poderia ter sido feita uma análise a partir da delimitação de um envelope de variação com vistas a comparar com outras formas usadas como conector oracional consecutivo em concorrência, no entanto não foi o nosso objetivo aqui. Observemos a seguir as ocorrências de (3) a (5), as quais trago transcritas da mesma forma que foram retiradas do corpus do NORPOFOR:

(3) 2- Inf.2: quantos anos que faz essa confusão toda quantos anos anos e anos aí ( ) o tempo passando e ela deixando com'é que vai fazer isso (refletindo nas pessoas que tão por fora)... chega o ambiente é pesado... pesado porque não consegue mais nem passar duas horas lá aí como é que faz? vamo ver se a gente resolve isso ((voz de terceiro)) (Inq. 4 - D2, 25/01/04).

\footnotetext{
${ }^{9}$ Destacamos que, quando iniciamos esta pesquisa, o projeto NORPOFOR estava em construção e não havia a disponibilização de mais entrevistas concluídas, por isso só tivemos acesso a três entrevistas gentilmente disponibilizadas pela professora Dra Aluiza Alves de Araújo, coordenadora do projeto.
} 
No excerto acima: podemos deduzir do discurso que está implícita a oração principal por exemplo que se encaixaria a oração encaixada encabeçada pelo chega. No entanto, fica claro, inferindo o tópico discursivo, que, devido à tanta confusão (daí temos a causa), a consequência é que o clima é pesado. E esse valor consecutivo é introduzido pelo conector chega. Podemos supor por exemplo a principal: (Já aconteceu tanta confusão ...chega o ambiente é pesado)

Observemos outro exemplo:

(4) - a gente tem que pedir primeiro a ele pra depois a gente meter as cara... ah:: mãe a senhora também é (carrasca) demais não demais não... demais não porque tudo que a gente vai fazer a gente tem que pedir a Deus meu filho TU::do... ainda ontem (taí) ainda ontem eu estive aí... até anteontem eu tava aqui sem saber notícia de uma prima minha que... por sinal que é essa minha tia... por sinal ela até morreu... e:.... a gente tava sem saber notícia dela como é que elas tavam quando foi ontem recebi um telefonema que uma delas tava muito mal...aí eu fui... de NOite ontem de noite fui baTER lá atrás da sogra duma pra saber onde é que a outra morava pra gente ir lá... pra mim ir lá... aí ela quando ela me viu chega chorou de alegria, eu digo vocês também não se comunica com a gente (se isola) não A. (Inq. 6-DID, 25/01/04).

A ocorrência acima é um caso peculiar. Ao recortarmos o período e omitirmos o chega "quando ela me viu (chega) chorou de alegria", teríamos tradicionalmente uma oração subordinada adverbial temporal. No entanto, a presença do chega deixa implícita um valor modalizador, uma apreciação do enunciador, onde exprimiria além da circunstância do tempo, mas sim algo no contexto situacional que seria o motivo do "choro de alegria" relatado. Dando a ideia de estar implícito algo do tipo quando me viu / a emoção era tanta/chega chorou de alegria. Bem como poderia ter a leitura considerando o titubeio próprio da fala: Aí ela... (quando ela me viu) chega chorou de alegria. Reescrita desse modo ficaria mais apreensível: Ao me ver ela chega chorou de alegria. Nesse sentido, o quando ela me viu seria um tipo de plano de fundo, uma informação complementar. Em ambas, o chega teria o valor de expressar consequência. Fica aparente o uso do chega como um recurso expressivo, como se fosse um expletivo da apreciação do enunciador.

Eis a última amostra do corpus NORPOFOR aqui analisada:

(5) - ... eu com com... com doze ano eles achava que eu nunca ia pular a janela porque achava que eu tinha medo de pular a janela olha... só que eu abri a janela... puxei assim a janela encostei a janela que a janela puxando ela ficava encostada né?... encostei a janela que ela tinha assim ( ) a pedra era bem larga ( ) só que::... joguei um pacote que eu fiz duas roupa uma chinela um caneco meu de beber á:gua... botei tudinho num saco e rebolei lá embaixo... rebolei lá embaixo e disse seja o que Deus quiser que eu TODA vida eu tive isso comigo... toda vida eu dizia seja o que Deus quiser e PÁ pulei 
quando eu pulei caí embai/ ((pancadas em uma mesa)) ah:: meu Deus... chega quase eu morro... mesmo assim. (Inq. 6-DID, 25/01/04).

Temos, no trecho, o relato de um acidente sofrido pelo informante. Ao final, fala de sua queda e, nas entrelinhas, quando apela a Deus, deixa clara a ideia de estar relembrando a gravidade da queda deixada em suspenso na sua narrativa e, logo em seguida, diz chega quase eu morro. Depreende-se daí a mensagem: /A queda foi muito feia/chega quase eu morro. Embora não haja a efetivação verbal, está clara a intenção comunicativa no falante ao narrar a queda e a põe como causa e a consequência foi quase morrer, segundo sua apreciação.

Registramos também ocorrência do chega como conector consecutivo em músicas populares, aqui registrada uma do gênero "arrochadeira", bastante escutado entre os jovens da comunidade de fala em questão. Esse trecho destacado em (6) foi coletado em uma academia de musculação em setembro de 2020 em Fortaleza na ocasião em que era ouvida e cantada por jovens ali presentes.

(6) [...] bate, bate na xereca que chega me machucou" (MC DRIKA; MC ROGERINHO, 2020).

No trecho, cabe destacar que, na oração principal, embora a forma verbal esteja no presente do indicativo, é dedutível a partir da narrativa presente na letra da música que se trata de referência a um evento no passado. O eu-lírico estaria referindo-se a algo que lhe sucedeu no passado. Inclusive, na oração encaixada (me machucou), o verbo vem no pretérito. Poderia ser lida de outra forma, como:

(6a) bateu, bateu tanto na xereca que me machucou.

(6c) bateu, bateu tanto na xereca chega me machucou.

O chega em (6) estaria atuando como uma forma expletiva, uma modalização do indivíduo sobre toda a cláusula "me machucou". Seria um estágio intermediário ao que seria possível em (6c). Evidenciamos a ocorrência do chega como conector oracional consecutivo no corpus linguístico do NORPOFOR, bem como nos demais exemplos da observação direta do autor trazidos ao longo do texto para demonstrar o fenômeno. Trataremos a seguir de traçar o percurso da mudança dessa gramaticalização a partir dos dados sincrônicos e analisar o processo à luz de princípios que coadunam no tratamento da mudança linguística.

\section{Percurso da mudança - uma Projeção}

Nos estudos sobre gramaticalização, há um consenso no que diz respeito a que conjunções se originem de verbos, substantivos e advérbios e que, na evolução das línguas, as 
conjunções apareceram depois dos verbos e não o inverso. Considerando aspectos morfossintáticos, inferimos que as conjunções são mais gramaticais do que verbos, substantivos e advérbios. Sobre esse percurso da evolução das conjunções, Martelotta (2011, p. 64) afirma:

Sabemos, através do estudo do processo de gramaticalização em várias línguas, que conjunções são provenientes de verbos, substantivos e advérbios. Aplicado à hipótese de uma evolução gradual das línguas, esse fato leva à hipótese de que verbos, substantivos e advérbios apareceram antes e que conjunções surgiram em um estágio posterior na evolução das línguas.

Um exemplo que nos parece pertinente recordar é o do item linguístico embora, que se gramaticalizou na língua portuguesa, pois se assemelha, a nosso ver, ao caso aqui tratado da forma chega por ter sua origem em uma construção gramatical: em boa hora, a qual resultou em conjunção embora. Araújo (2013) discorre sobre os princípios da gramaticalização e expõe as etapas da construção em boa hora até sua gramaticalização como conjunção concessiva. O autor destaca que o item seria um caso prototípico por contemplar todos os princípios de Hopper (1991). O autor também faz um percurso diacrônico mostrando as reanálises e implicaturas conversacionais que a construção em boa hora sofreu até o estágio de gramaticalização atual como conjunção concessiva.

A partir dos dados sincrônicos aqui apresentados, constatamos a ocorrência de chega atuando como conector oracional consecutivo, uma forma gramaticalizada no repertório do fortalezense. Decidimos então projetar, baseados no modelo da gramática das construções e no princípio do uniformitarismo, que essa forma se originou da construção que chegou a. Ao considerarmos esse conjunto como uma construção, entendemos que o significado expressado é o do todo e não o valor composicional, fruto da junção do valor individual de cada elemento. Com isso, essa construção estaria sujeita a sofrer alterações como qualquer unidade linguística do sistema linguístico, inclusive processo de gramaticalização.

A produtividade de gramaticalização de conjunções a partir de construções gramaticais (simples ou complexas) é muito rica na língua portuguesa. Além do exposto caso do embora, temos o caso do aí, um caso prototípico, que passa de dêitico espacial a conjunção consecutiva. Na literatura, temos vários exemplos de conectivos em língua portuguesa que seguem o cline de gramaticalização espaço > tempo > texto (HEINE; CLAUDI; HUNNEMEYER, 1991). Muitas conjunções com valor conclusivo foram criadas em língua portuguesa seguindo esse cline de gramaticalização, é o que ocorreu com: por isso, aí, então, entretanto, portanto, tanto que etc. (MARTELOTTA, 2011, p. 84). Consideramos relevante destacar esses exemplos de gramaticalização de conjunções, pois o verbo chegar, embora não seja um dêitico, mas sim por possuir inerentemente a carga semântica que indica deslocamento espacial, passaria, assim, pelo cline deslocamento espacial > deslocamento temporal > conector consecutivo. Analogamente aos 
dêiticos citados, assumimos que isso haja ocorrido ao chega no falar fortalezense a partir da construção que chegou a.

Supomos que o processo de gramaticalização a partir da construção que chegou a, cuja forma verbal está em terceira pessoa e no singular, no tempo pretérito perfeito, teria sido propiciado por serem consideradas formas não-marcadas, ou seja, mais recorrentes e passíveis a generalizações. ${ }^{10}$ Por exemplo, no seguinte enunciado:

(7) Carlos chegou ao seu juízo final (exemplo do próprio autor).

Em (7), o ponto final do evento não indica mais que houve deslocamento espacial ou temporal, mas sim pode indicar o resultado de um processo, em que a interpretação possível da causa, implícita, seriam suas atitudes, que o levaram a uma consequência (seu juízo final), nesse caso um final onde pagaria pelos seus erros ou acertos. Por possuir um sujeito de terceira pessoa, provavelmente esse seja o contexto inicial de ocorrência dessa extensão de uso da forma chega e favoreceu essa reanálise, assumindo um valor consecutivo, por extensão.

Nas cláusulas subordinadas consecutivas aqui em foco, embora a inerente factualidade da consequência implique falar do passado (independentemente do aspecto e codificação verbal), percebemos que, ao fim do processo, constata-se uma "acomodação" da forma verbal na terceira pessoa do singular do presente do indicativo, a forma chega, por ser menos marcada cognitivamente, mais recorrente, mais simples e para atender à acomodação fonética, i.e., um processo de assimilação ${ }^{11}$ ocorrida na construção que chegou $a$. $O$ papel da frequência nesses processos de difusão e consolidação é fundamental.

Isso se observa já na etapa final, quando o termo já está gramaticalizado e inserido no paradigma das conjunções consecutivas, já não mais concordando com o sujeito nem com o tempo verbal da oração principal:

(8) Eles trabalham muito (todo dia) chega ficam quebrado quanto 'tão em casa (exemplo do próprio autor).

(9) Eu peguei muito em enxada chega fiquei todo calejado. Olha aqui! (exemplo do próprio autor).

Segundo Bybee (2003), o papel da frequência é fundamental na implantação e manutenção da mudança linguística. Como o expõe Martelotta (2011, p. 56):

Os eventos de uso, aliás, são cruciais para a continuidade da estruturação do sistema, já que não representam apenas o produto do sistema

\footnotetext{
${ }^{10}$ Faz-se oportuno, para maiores detalhes, consultar o princípio de marcação proposto por Givón (1995) e revisto em Martelotta (2008).

${ }^{11}$ Uma alteração envolvendo um fonema que decorre da influência exercida por outro fonema vizinho de som igual ou semelhante.
} 
linguístico do falante, mas fornecem o input para os sistemas de outros falantes [...]. Todo esse mecanismo, veiculado pelo uso, ocasiona reanálises, analogias e outros processos que implicam alterações e extensões no emprego das expressões linguísticas. Os novos usos provenientes desses processos podem ter sua frequência aumentada, a ponto de transcender os limites do ambiente comunicativo em que são empregados, sendo assim incorporados ao sistema.

Sugerimos o seguinte esquema da trajetória de mudança do fenômeno:

\section{Esquema 6}

que > que chegou a > que chego' a > que cheg'a > chega

Ilustramos a seguir essas etapas.

(10) O Carlos comeu tanto que passou mal > contexto prototípico.

(10a) O Carlos comeu tanto que chegou a (o ponto de) passar mal > Como forma expletiva em rearranjo discursivo e por extensão metafórica.

(10b) O Carlos comeu tanto que chego' a passar mal > erosão fonética

(10c) O Carlos comeu tanto que cheg’a passou mal > univerbação e reanálise sintagmática.

(10d) O Carlos comeu tanto chega passou mal > implicatura convencional (metonímia = 'chega' (parte) por 'que chegou a'(todo), reanálise sintagmática (elimina-se o que).

(10e) Carlos e João comeram tanto chega passaram mal. (convencionado no sistema como integrante do paradigma dos conectores, invariável).

O estatuto semântico do verbo chegar prototipicamente implica deslocamento espacial e possui inerentemente um valor culminativo, i.e. indicando o ponto final de um processo ou ação, por extensão metafórica passa a indicar deslocamento temporal e logo passa também a expressar a culminância de processo ou ação que não implique necessariamente deslocamento espacial ou temporal.

Isso propicia o uso do verbo chegar junto à conjunção que de forma expletiva como em (10a), já sem indicar deslocamento espacial, passa a expressar consequência de um processo motivado por uma causa. Logo, propiciado pela frequência passa por etapas de redução fonética (10b) e univerbação e reanálise (10c) e sofrendo implicaturas conversacionais de base metonímica, depreende-se a parte chega pelo todo que chegou a em $(\mathbf{1 0} \mathrm{d})$. Esse processo é fruto da constante atualização na fala e das reanálises contextuais ${ }^{12}$ feitas pelos falantes na interação comunicativa. Por fim, a forma chega já gramaticalizada passa a ocorrer sozinha em outros contextos sintagmáticos sem o sujeito na terceira pessoa do singular, como em (10e),

${ }^{12}$ Vide Gonçalves et al. (2007, p. 49). 
estabelecendo a relação entre causa e consequência, já sem os traços morfossintáticos próprios da categoria verbo, assumindo traços da categoria conector oracional.

Inicialmente, postulamos que o verbo chegar passou a ocorrer ao lado do que em frases recorrentes na atualidade, como se vê nessa notícia de blog:

(11) A Alemanha produz tanta energia renovável que chegou a pagar para os cidadãos consumirem (GONÇALVES, 2016).

Como observado no exemplo (11) e nos exemplos anteriores (2a) e (10a), o verbo chegar, por extensão metafórica, na expressão de consequência e em um rearranjo sintagmático com vistas a incutir maior expressividade, passou a ocorrer junto à conjunção que (protótipo da categoria), como uma estratégia discursiva de realce da consequência do processo (causa) exposta na oração principal. Ao invés de dizer A Alemanha produz tanta energia renovável que chegou a pagar para os cidadãos consumirem pode-se dizer com o mesmo valor de verdade A Alemanha produz tanta energia renovável que pagou/paga para os cidadãos consumirem.

Com isso, depreende-se que o uso do verbo chegar junto à conjunção que se generaliza e passa a ser reconhecido como o bloco que chegou a, que indica consequência e, desse modo, tem seu uso ratificado e estendido por analogia e reanálise a outros contextos de uso que não sejam, necessariamente, com sujeitos na terceira pessoa do singular e com verbos da principal no passado, possibilitando a gramaticalização de chega. Na fala do fortalezense, não raramente se escutam frases como em (8), (9) e as seguintes:

(12) Rapaz, o negócio foi tão rápido, machooo... chega (eu) num tive nem tempo de reagir, mahh... (exemplo do próprio autor).

(13) Rapaz, a Marina humilhou tanto o pobizim chega o cara ficou todo errado, todo sem jeito. (exemplo do próprio autor).

Voltando à gramaticalização do chega exposta nas etapas anteriores, após a ratificação da construção que chegou a aparecer contextualmente e ser vista como uma unidade linguística portadora do significado gramatical de consequência, devido ao papel da frequência, passa a sofrer redução fonética, como em (10b) e logo a univerbação em (10c). Por fim, em (10d), devido a implicaturas conversacionais ocasionadas por processos inferenciais e metonímicos, ilustrando o mecanismo de inferência sugerida, ${ }^{13}$ o chega, propiciado pela semântica original do verbo, passa a ser suficiente na expressão da relação causa/consequência, passando a ser interpretada como desnecessária a presença do que, acarretando uma reanálise sintagmática em que o verbo da encaixada se flexiona, como seria com o conector prototípico que em (10).

\footnotetext{
${ }^{13}$ Segundo Martelotta (2011 p. 80-85), no evento comunicativo, falante e ouvinte, valendo-se do contexto morfossintático e das informações extralinguísticas, negociam o sentido de maneira interativa, ou seja, o interlocutor, ao exercer seu turno comunicativo, sugere que o receptor infira novos sentidos, trabalhando com dados contextuais específicos daquela situação comunicativa.
} 
Com a frequência de uso, a forma chega, gerada por implicatura conversacional, inferências e reanálises, repete-se em outros enunciados, propagando-se entre os usuários da comunidade linguística, generaliza-se e convencionaliza-se, resultando na implicatura convencional. Com isso, acarreta a gramaticalização no repertório da comunidade de fala, pois o chega passa a ser usado não apenas em contextos com sujeito na terceira pessoa do singular e com verbos da principal no passado, passando esse novo valor a ser aceitado pela comunidade e estendendo-se a novos contextos, desse modo, o chega incorpora esse valor de conector consecutivo de forma mais definitiva e convencional no repertório linguístico dos falantes fortalezenses.

\section{ConCLUSÃo}

Defendemos que a forma chega gramaticalizou-se no vernáculo fortalezense a partir da construção gramatical que chegou $a$, mantendo o valor aspectual culminativo inerente ao verbo chegar presente na construção. Acreditamos que as etapas do processo aqui expostas descrevem satisfatoriamente o processo. Ao considerarmos o esquema 4, constatamos que, à semelhança de outros clássicos exemplos de gramaticalização, como o do embora citado anteriormente, a partir de um elemento menos gramatical, no caso uma forma verbal flexionada na construção que chegou a originou-se uma forma mais gramatical e invariável, a conjunção consecutiva chega. Vale ressaltar que cumpre os parâmetros da gramaticalização de Heine e Kuteva (2007), conforme exposto.

Além disso, cremos ser pertinente propor que, além da mudança mencionada, a forma chega parece veicular um valor modalizador, uma apreciação mais emotiva do enunciador sobre a relação causa/consequência informada no enunciado.

Consideramos que, pelo fato de o valor do verbo chegar representar de forma mais concreta (por extensão metafórica) a consecução da motivação/causa veiculada na oração principal, o falante interpreta que seu valor traria mais expressividade junto à conjunção que, formando a construção que chegou a. E que, a partir de coordenadas metonímicas e inferências sugeridas no contexto que acarretam implicaturas conversacionais, reanálises contextuais e com o processo de erosão fonética e univerbação, da construção resulta o item chega, que, com a frequência de uso, acaba por convencionalizar-se e assumir a função da conjunção consecutiva prototípica que, sem prejuízo para a gramaticalidade da sentença, otimizando a comunicação, dando-lhe maior expressividade, estando em consonância com o que prevê a teoria funcionalista e da Linguística Centrada no Uso.

Faz-se relevante mencionar que se nos mostrou produtiva a perspectiva teórica aqui adotada para observar e analisar o fenômeno. E que, a partir dos dados observados, este estudo aponta a viabilidade de uma pesquisa mais acurada tanto seguindo os pressupostos teóricos do Funcionalismo Linguístico, com suporte na Linguística Centrada no Uso, bem como se 
mostra campo fértil para a Sociolinguística Variacionista. Um empecilho encontrado é a falta de um corpus linguístico consolidado do vernáculo fortalezense disponível para análise até então, mas que se sabe que se encontra em vias de finalização.

Observando o fenômeno em questão se nos fazem relevantes os questionamentos seguintes: Como essa mudança é possível? Como e quando isso aconteceu na comunidade de fala em foco? Quem faz mais frequentemente uso dessa forma, homens, mulheres, jovens, idosos, indivíduos com maior ou menor escolaridade e etc.? Apontamos, também, a partir de dados observados pelo próprio autor e de uma amostra, embora pequena, de um corpus linguístico representativo consolidado do falar fortalezense em contraste com dados da variedade padrão que espelham a tradição, a pertinência de se fazer um estudo sociolinguístico com vistas a apontar a força da variável chega / que / que chegou a / que chega / na função de conector consecutivo no falar fortalezense e, assim, apontar como a variante chega se espraia em relação à estrutura social. Esses questionamentos dão subsídios a uma futura análise da Sociolinguística Variacionista.

Desse modo, concebendo a língua como um produto histórico, inerentemente dinâmico e, consequentemente, sua gramática também como produto desse caráter dinâmico, se nos faz patente o caráter emergente da gramática, passível às pressões do uso, atualizada e retroalimentada na fala, i.e., se faz simultaneamente input e produto. A partir disso, buscou-se projetar e analisar um provável percurso da forma chega, conector consecutivo, desde sua origem como verbo na construção que chegou a e, desse modo, indicar os processos cognitivos e os processos inerentes à interação comunicativa que explicariam essa gramaticalização, consentida aqui como consolidada no vernáculo da comunidade de fala fortalezense, uma vez que em contraste com a variedade padrão da língua portuguesa, e que esta espelha a tradição, mostra-se como uma forma inovadora, não dicionarizada, fruto da criatividade humana, refletindo a gramática como emergente a partir da interação comunicativa dos indivíduos no exercício da faculdade da linguagem.

Valendo-nos do princípio do uniformitarismo, que prevê que as forças que atuam no presente são as mesmas que atuaram no passado, mostra-se pertinente a projeção feita do percurso da mudança aqui exposto. Além do princípio da unidirecionalidade, em que um item menos gramatical passa a um mais gramatical, conforme exposto neste estudo.

Confirmam-se, como em outros casos de gramaticalização na língua portuguesa, padrões de regularidade da mudança linguística, além da atuação da criatividade humana e os fatores sociocognitivos inerentes ao processo de gramaticalização.

Existem já trabalhos sobre a gramaticalização do verbo chegar, como o Rocha e Sousa (2019) que, embora tenha outro recorte do objeto de estudo, nele se expõe uma escalada na abstratização desse verbo, em que há perda do sentido de deslocamento espacial de X a Y, como aqui proposto 
Reconhecemos que o estudo aqui exposto sinaliza que é oportuno uma pesquisa mais robusta de descrição e análise sobre o estudo da gramaticalização do verbo chegar e acreditamos que o presente trabalho veio contribuir para esse fim.

\section{REFERÊNCIAS}

ARAÚJO, A. A. de. O projeto norma oral do português popular de Fortaleza-Norpofor. Cadernos do CNLF, v. XV, n. 5, t. 1., p. 835-845. Rio de Janeiro: CiFEFiL, 2011.

ARAÚJO, A. A. de; VIANA, R. B. de M.; PEREIRA, M. L. de S. (Org.) Fotografias sociolinguísticas do falar de Fortaleza - CE [recurso eletrônico]. 2. ed. - Fortaleza: EdUECE, 2020.

ARAÚJO, F. J. N. de. V. Cadernos de pós-graduação, n. 5, p. 39-53, 2013.

BYBEE, J. Mechanisms of change in grammaticization: the role of frequency. In: JOSEPH, B.; JANDA, R. D. (eds.) The Handbook of historical linguistics. Oxford: Blackwell Publishing Ltd., 2003.

CAVALCANTE, S.; SOUZA, A. Linguística Cognitiva: uma breve introdução. In: HERMONT, A. B.; ESPIRITO SANTO, R. S.; CAVALCANTE, S. (Orgs.). Linguagem e Cognição: diferentes perspectivas. 1. ed. Belo Horizonte: Editora PUC Minas, 2010. 248p.

CUNHA, A. F. Funcionalismo. In: MARTELOTTA, M. E. (org.). Manual de Linguística. São Paulo: Contexto, 2008.

CROFT, W.; CRUSE, D. A. Cognitive Linguistics. Cambridge: Cambridge University, 2004.

CROFT, W. Radical construction grammar: syntactic theory in typological perspective. Oxford: Oxford University Press, 2001.

DU BOIS, W. E. B. Dusk of Dawn, Transaction Publishers, New Jersey, 1984,

FERRARI, L. Introdução à Linguística Cognitiva. São Paulo: Contexto, 2011.

FERREIRA, A. B. de H. Dicionário Aurélio do Século XXI. 3. ed. Rio de Janeiro: Editora Nova Fronteira, 1999.

FILLMORE, C.; KAY, P.; O'CONNOR, C. Regularity and idiomaticy in gramatical constructions: the case of let alone. In: Language. 1988, v. 64, p. 501-538.

FRIED, M.; ÖSTMAN, J. Construction grammar: a thumbnail sketch. In: FRIED, M.; ÖSTMAN, J. (Ed.). Construction grammar in a cross-language perspective. Philadelphia: John Benjamins, 2004. p. 11-86.

GOLDBERG. A. Constructions. Chicago: University of Chicago Press, 1995. 
GOLDBERG. A. Constructions at work: the nature of generalization in language. Oxford: Oxford University Press, 2006.

GIVÓN, T. Functionalism and grammar. Philadelphia: John Benjamins, 1995.

GONÇALVES, S. C. L.; LIMA-HERNANDES, M. C.; CASSEB-GALVÃO, V. C.; CARVALHO, C. S. Tratado Geral Sobre Gramaticalização. In: GONÇALVES, S. C. L.; LIMA-HERNANDES, M. C.; CASSEB-GALVÃO, V. C. (Org.). Introdução à Gramaticalização. São Paulo: Parábola, 2007.

GONÇALVES, M. Alemanha produz tanta energia renovável que chegou a pagar para os cidadãos consumirem. Disponível em: www.tecnoblog.net/195517. Acesso em: ago. 2016.

GUY, G. As comunidades de fala: fronteiras internas e externas. In: Abralin, 2001. Disponível em: http://sw.npd.ufc.br/abralin/anais_con2int_confo2.pdf. Acesso em 20 ago. 2021.

HOPPER, P.; TRAUGOTT, E. Grammaticalization. Cambridge: Cambridge University Press, 1993.

HOPPER, P. J. On some principles of grammaticization. In: TRAUGOTT, E. C.; HEINE, B. (Eds.). Approaches to grammaticalization. v. I, Philadelphia, John Benjamins Company, 1991.

HEINE, B.; REH, M. Patterns of Grammaticalization in African Languages. AKUP-47, Cologne: Universitätzu Köln, Institut für Sprachwissenschaft, 1984.

HEINE, B.; CLAUDI, U.; HÜNNEMEYER, F. Grammaticalization: a Conceptual Framework. Chicago: The University of Chicago, 1991.

HEINE, B.; KUTEVA, T. The genesis of grammar: a reconstruction. Oxford: Oxford University Press, 2007.

KAY, P.; FILLMORE, C. Grammatical constructions and linguistic generalizations: The What's $\mathrm{X}$ doing Y construction. Language, 1999, 75, pp. 1-34.

LABOV, W. Padrões sociolinguísticos. 1. ed. Tradução de Marcos Bagno, Marta Maria Scherre, Caroline Rodrigues Cardoso. São Paulo: Parábola, 2008. 392 p.

LEHMANN, C. Thought on Grammaticalizaton: a Programatic Sketch. Köln: Arbeiten des Kölner Universalien 49 - Projects, v. 1, 1982.

LICHTENBERG, F. On the Gradualness of Grammaticalization. In: TRAUGOTT, E.; HEINE, B. (Orgs). Approaches to Grammaticalization. Amsterdam: John Benjamins, 1991, p. 37-80.

MARTELOTTA, M. E (Org.). Manual de Linguística. São Paulo: Contexto, 2008.

MARTELOTTA, M. E. Mudança linguística: uma abordagem baseada no uso. São Paulo: Cortez, 2011. 
MC DRIKA; MC ROGERINHO. Foi bate bate. 2020. Disponível em: https://youtu.be/ YYqtVYUaBjU. Acesso em: 1 nov. 2020.

MICHAELIS. Michaelis online. Editora Melhoramentos Ltda, 2009, disponível em: Michaelis. uol.com.br. Acesso em: 25 abr. 2016.

PAIVA, M. C.; DUARTE, M. E. L. Mudança Linguística: observações no tempo real. In: MOLLICA, M. C.; BRAGA, M. L. (Org.). Introdução à Sociolinguística: o tratamento da variação. São Paulo: Contexto, 2003.

PRIBERAM. Dicionário Priberam da Língua Portuguesa, 2016. Disponível em: https://www. priberam.pt/dlpo/chega. Acesso em: 25 abr. 2016.

ROCHA, N. C. B. B. F.; SOUSA, V. V. Gramaticalização do item linguístico chegar: analisando um verbo de/em movimento no Português. Id on Line Rev. Mult. Psic. v.13, n. 44, p. 132-147, 2019.

SOUZA, A. L. A Gramática de Construções 2010. Disponível em: http://asouza.people.ua.edu/ uploads/3/8/0/5/38053611/2010_souza.pdf. Acesso em: maio 2016.

TOMASELLO, M. Constructing a language: a usage-based theory of language acquisition. Cambridge/London: Harvard University Press, 2003.

WEINREICH, U.; LABOV, W.; HERZOG, M. Fundamentos empíricos para uma teoria da mudança linguística. 2. ed. Tradução de Marcos Bagno. São Paulo: Parábola, 2009. 97 p.

WERNER, H.; KAPLAN, B. Symbol-formation: an organismic developmental approach to language and the expression of thought. New York/London/Sidney: Wiley, 1963.

Recebido para publicação em: 1 jul. 2021. Aceito para publicação em: 3 set. 2021. 